\title{
Transformation of Staff Efficiency with Talents Enrichment: A Dynamic Capabilities View
}

\author{
Mohamad Faizal Ahmad Zaidi \\ School of Technology Management \& Logistics, \\ College of Business, Universiti Utara Malaysia, 06010 Sintok, Kedah Malaysia \\ mdfaizal@uum.edu.my, +6049287024
}

DOI: $\quad$ 10.6007/IJAREMS/v5-i1/2065 URL: http://dx.doi.org/10.6007/IJAREMS/v5-i1/2065

\begin{abstract}
This article aims to enrich our understanding on the concept of dynamic capabilities (DCs) according to a recent study on service quality and customer satisfaction for one agency in the public sector of Malaysia. Based on the findings, the discussion is focused on the element of staff and the dimension of policy development according to the critical responses. Through the lens of DCs, this article explains how the transformation processes of staff efficiency with talents enrichment will possibly increase the customer satisfaction towards a better policy development. This shows that the concept of DCs can be demonstrated in the public sector (e.g., non-profits oriented), which is still rarely discussed relatives to the private sector (e.g., profits oriented). At the ends, a proposition for empirical research based on the conceptual framework is suggested, in order to verify the mediating effects of talents enrichment (transformation processes) in the relationship between staff efficiency and policy development.

KEYWORDS: Customer satisfaction; internal resource; Malaysia; public sector; service quality JEL Classification: H11, 020
\end{abstract}

\section{Background}

This article is based on a recent study intended to develop a strategic plan for one agency in the public sector of Malaysia. Based on the results, this article has narrowed down the issues on staff efficiency and policy development according to the critical responses. The findings imply that the relationship between staff efficiency and policy development might be influencing the development of a strategic plan for the public sector in Malaysia. This issue is being emphasized under the transformation plan for the public sector in order to improve service quality towards a better customer satisfaction. Since the discussion is focusing on the intangible resources (i.e., staff efficiency) as the source for competitive advantage, this article refers the transformation processes of staffs as a form of dynamic capabilities (DCs) (Teece, Pisano, \& Shuen, 1997). This concept will helps us to understand how the transformation processes could be related to the organizational objectives. Consequently, this will further enrich our knowledge on the concept of DCs via transformation processes in the context of public sector that is still rarely discussed in literature. 


\section{The Transformation Plan for Public Sector in Malaysia ${ }^{1}$}

Globalization has placed many countries towards various challenges with high level of competitiveness, advancement in science and technology, and talent competency. In Malaysia, these changes have threatened the existing policies and strategies of the government towards obsolescence. Since the public sector plays major responsibilities in the face of this new reality, the government reputation needs to be increased in line with the pace of changes. As such, it was believed that the public sector could be more dynamic and agile if the public servants possessing high level of knowledge and skills. Therefore, public servants as the main driver of public sector need to be more responsive to the changes in environment and the needs of citizens. As a result, they have to strengthen their capabilities in order to deliver the duties efficiently. To do this, the public sector needs to impose some strategic changes in the planning processes and human resource management to remain relevant. For the action, all agencies have to take some initiatives for the transformation processes that require structured continuous changes in the action, attitude, and environment towards achieving strategic outcomes.

To be successful, a continuous and impactful momentum in the transformation processes of public sector demanding a high level of commitment and active participation of all stakeholders (especially the staffs themselves). Therefore, enculturing of good values, such as patriotism and integrity will be able to change the presentation, behavior, paradigm, trait, and norm of the public servants towards a more innovative, creative, competitive, and productive services of the public sector. As a result, a transformation plan for the public sector has been created by the Public Service Department of Malaysia. This transformation plan is a document consisted of an implementation plan for every agency in the public sector. This plan will inspire all public agencies to change from what they are now to what they should be. In order to face with the challenges and to deal with the issues in human resource development, the transformation plan of public sector has emphasized on building and maintaining the talents, strengthening the organization, reinforcing the delivery processes of public sector towards citizen-centric, increasing the involvement, cooperation and scope, and enculturing the patriotism and integrity. The descriptions of the five cores of transformation plan for the public sector in Malaysia are shown in Table 1.

1 The information in this section is sourced from the "Manual Penyediaan Pelan Transformasi Perkhidmatan Awam". This manual is written in Malay. The details of this manual can be accessed from http://docs.jpa.gov.my/docs/transformasi/Manual/Manual_Transformasi.pdf 
Table 1: The five cores of transformation plan for the public sector in Malaysia

\begin{tabular}{|c|c|c|}
\hline Core & Name & Description \\
\hline - First & $\begin{array}{l}\text { Talents } \\
\text { enrichment }\end{array}$ & $\begin{array}{l}\text { To produce civil servants with high knowledge, } \\
\text { competencies, talents and skills in various fields to } \\
\text { improve performance, productivity and innovation. }\end{array}$ \\
\hline - Second & $\begin{array}{l}\text { Organizational } \\
\text { reengineering }\end{array}$ & $\begin{array}{l}\text { To increase the capacity and improve the organizational } \\
\text { structure through process re-engineering to make it } \\
\text { more dynamic, agile and flexible and able to adapt to } \\
\text { change in order to continue to provide the best service } \\
\text { according to the requirements and needs. }\end{array}$ \\
\hline - Third & $\begin{array}{l}\text { Citizen- } \\
\text { oriented } \\
\text { service } \\
\text { delivery }\end{array}$ & $\begin{array}{l}\text { To emphasize on strengthening the efficiency and } \\
\text { effectiveness of public service delivery and client-based } \\
\text { citizens (citizen-centric) to be fast, precise, high quality, } \\
\text { proactive and responsive. }\end{array}$ \\
\hline - Fourth & $\begin{array}{l}\text { Inclusive and } \\
\text { conclusive }\end{array}$ & $\begin{array}{l}\text { To emphasize on business and expand its network of } \\
\text { strategic collaborations within and outside the country to } \\
\text { get views and feedback that is more inclusive and } \\
\text { conclusive. }\end{array}$ \\
\hline - Fifth & $\begin{array}{l}\text { Value } \\
\text { nurturement }\end{array}$ & $\begin{array}{l}\text { To emphasize on civilizing patriotism, moral values, } \\
\text { ethics and integrity for public servants who bore love for } \\
\text { the country, well-mannered and highly ethical. }\end{array}$ \\
\hline
\end{tabular}

\section{A Review of a Study on Public Sector in Malaysia}

Prior to the writing of this article, a study on service quality and customer satisfaction was performed in 2015 as part of the planning to develop a strategic plan for one agency in the public sector of Malaysia. Although not directly associated to the mentioned study, this article was written according to the reports as a way to disseminate some of the relevant findings. At first, a literature was reviewed to build a solid bases and facts for the study. This was then followed with the building of research instruments through a series of workshops at the management level of the agency. As the outcomes, a set of questionnaires for measuring service quality was built on the 7S McKinsey model (Hanafizadeh \& Ravasan, 2011), while customer satisfaction was measured with nine dimensions of services provided by the agency. Meanwhile, the respondents for the service quality are the staffs of the agency itself, and the respondents for the customer satisfaction are the customers of the agency (i.e., from both government and non-government organizations). The data were collected online via SurveyMonkey within a period of 14 days. The surveys have managed to collect 77 internal responses for the service quality, and 273 external responses for the customer satisfaction. These data were interpreted with the SPSS ver.19 statistical tool for exploratory and descriptive analyses. 
As shown in Table 2, the findings on service quality have suggested that the elements of structure and staff were rated below the average score of $66.81 \%$, where each of them have managed to achieve only $65.50 \%$ and $53.72 \%$ respectively. In a more detail, it appears that staff was the only element rated lesser than $60.00 \%$. This means the staffs of public sector (which are the internal respondents) believed that their capacities to deliver the tasks were insufficient to achieve the organizational objectives. With the findings in mind, this article focuses on the worst (soft) element of service quality (i.e., staff efficiency), which is intangible in nature, valuable and difficult to build in contrast to the hard element of service quality, i.e., the structure.

Table 2: The level of achievement by the elements of service quality

\begin{tabular}{|c|c|c|}
\hline Category & Element of 7S McKinsey & Level (\%) \\
\hline - Hard & Strategy & 73.75 \\
\hline - Hard & System & 69.75 \\
\hline - Soft & Skill & 68.50 \\
\hline - Soft & Style & 68.50 \\
\hline - Soft & Shared Value & 68.00 \\
\hline - Hard & Structure & 65.50 \\
\hline - Soft & Staff & 53.72 \\
\hline
\end{tabular}

Meanwhile, Table 3 shows nine dimensions of services for customer satisfaction, namely management service, customer service, quality service, counter service, project management, event management, training, policy development, and general. It is clear that the respondents have rated policy development with the highest importance (I) score of 4.89 and the satisfaction $(S)$ score of 3.71 (out of 5.0). Although the I-S score for policy development is not the highest (1.18), the difference is not too much from the score of event management (1.27). Since the scores were rated by the customers of the agency itself, it is relevant to focus on the policy development as the most critical dimension of customer satisfaction. 
Table 3: The score of nine dimensions of customer satisfaction

\begin{tabular}{lccc}
\hline \multirow{2}{*}{ Dimension } & \multicolumn{3}{c}{ Score } \\
\cline { 2 - 4 } & Importance (I) & $\begin{array}{c}\text { Satisfaction } \\
(S)\end{array}$ & I-S \\
\hline - Policy development & 4.89 & 3.71 & $\mathbf{1 . 1 8}$ \\
- Event management & 4.50 & 3.23 & 1.27 \\
- Counter service & 4.32 & 3.60 & 0.72 \\
- Training & 4.24 & 3.92 & 0.32 \\
- Management service & 4.19 & 3.48 & 0.71 \\
- Quality service & 4.11 & 3.62 & 0.49 \\
- General & 3.98 & 3.34 & 0.64 \\
- Project management & 3.86 & 3.56 & 0.30 \\
- Customer service & 3.69 & 3.65 & 0.04 \\
\hline
\end{tabular}

With these findings in mind, it can be summarized that the element of staff (for service quality) and the dimension of policy development (for customer satisfaction) are the most crucial variables to be considered for building a strategic plan for the public sector in Malaysia. Since the element of staff is the weakest performer of service quality, while policy development is the most important dimension of customer satisfaction, it can be concluded that there was a noticeable gap to improve service quality towards customer satisfaction. Therefore, the relationship between staff efficiency and policy development should be investigated further (see Figure 1).

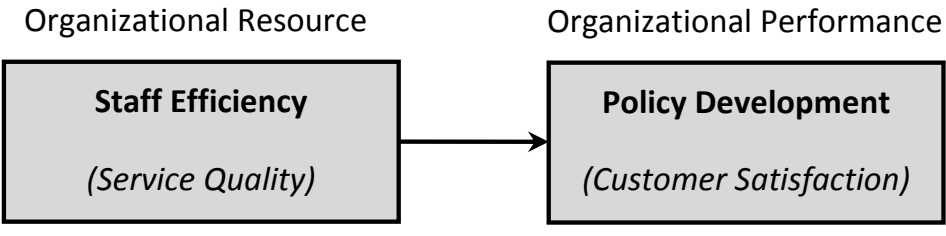

Figure 1: The basic relationship between staff efficiency and policy development

The relationship in Figure 1 needs a more detail discussion as it comes from the actual study that was responded by both internal (for service quality) and external (for customer satisfaction) respondents. Since an organization with strong resource transformation processes is better at leveraging the existing resources to capitalize on the opportunities (Ellonen, Wikstrom, \& Jantunen, 2009), it might be possible if the capacity to transform the staff efficiency towards a better service quality could be translated into a policy development that would improve customer satisfaction. However, the question yet to be answered is how the transformation processes of staffs should be done? After considering that the human resource 
is an important intangible resource of the organization, this article has decided to look into the concept of DCs to explain the transformation processes of resource (i.e., staff efficiency).

\section{Dynamic Capabilities and Transformation Processes}

Generally speaking, the concept of DCs has received a handful of debates (Zahra, Sapienza, \& Davidsson, 2006) and criticisms since it is still relatively new (Czakon, 2009). For instance, all of the existing definitions were claimed to be unclear, in which none of them were able to define the meaning of DCs satisfactorily (Wang \& Ahmed, 2007). As such, although DCs is linked to the organizational ability for integrating, building, and reconfiguring the resources (Teece, 2007) that are valuable, rare, inimitable, and non-substitutable (Teece, Pisano, \& Shuen, 1997), some scholars have argued that these resources should be transferable (Helfat \& Peteraf, 2003). Besides that, this concept needs further explanation since there was no clear direction to achieve (Salomo, Gemunden, \& Leifer, 2007) and foster it (Wu, 2009). Despite of these issues, a recent study has listed four common perspectives of DCs and performance, namely (1) a direct effects of DCs on performance, (2) a resource moderation effects in the relationship between DCs and performance, (3) a resource mediation effects in the relationship between DCs and performance, and (4) DCs mediation effects between resources and performance (Eriksson, 2014).

In addition, although the themes of previous studies on DCs were generally on the foundations and applications, interrelationships with other theoretical perspectives, issue of governance structure, and transformation processes and entrepreneurship, it was found that DCs transformation processes is still rarely studied relative to the other themes (DiStefano, Peteraf, $\&$ Verona, 2010). Since DCs concept has received a handful of criticisms on the purposes (Helfat \& Peteraf, 2009), DCs should be relevant to be demonstrated in the context of public sector to enhance our knowledge on the importance of organizational resources and transformation processes to achieve the organizational objectives. Furthermore, the public organization is chosen since DCs is relatively less discussed in this sector (e.g., for non-profit services), in contrast to the private sector (e.g., for profit services). Thus, the focus of this study on the transformation processes of public sector is timely relevant. For the purpose of this study, a DCs conceptual framework as shown in Figure 2 is referred to. This conceptual framework that is based on the fourth perspective of DCs, as highlighted by Eriksson (2014), proposes a mediation effect of DCs (through transformation processes) in the relationship between resource and performance.

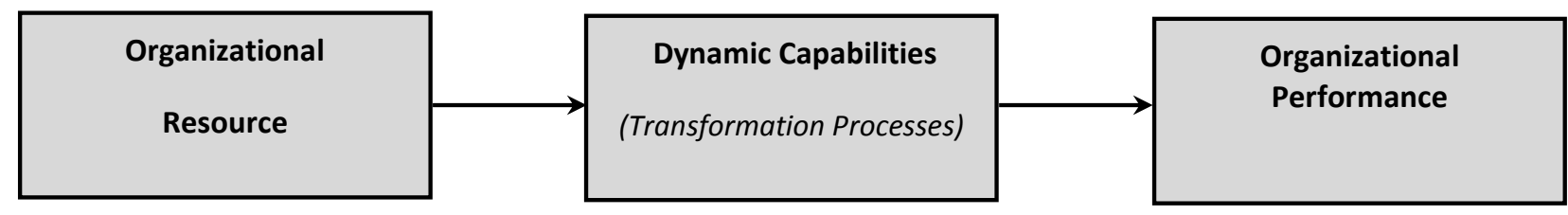

Figure 2: A mediation effect of DCs between resource and performance

Theoretically, the transformation processes can be performed through addition, deletion, or modification of the resources (Helfat, et. al., 2007) at the birth, growth, change, and (or) decline stages of their lifecycles. The resource transformation can be done by any combination of these processes, namely renewal, recombination, redeployment, replication, retrenchment, and 
retirement. Basically, resource renewal is performed in response to the crisis by improving the current resources with new alternative within the same market and product (in this case is the public sector). Resource recombination is performed to combine difference resources, e.g., between manufacturing and R\&D, which can be the alternative to resource renewal also for the same market and product. Resource redeployment is performed to apply identical resources across different markets with similar product or service, which can be done either by transferring or sharing the resources between old and new markets. Meanwhile, resource replication involves transferring of resources from one economic setting to another if the benefit exceeds the cost. Since not all transformation processes is for the growth, resource retrenchment should be taken if the productivity of a product started to decline. This reconfiguration type is to respond to the external threats that force the organization to limit the production capacities in a less severe situation. Under severe situation, resource retirement should be performed to release the burdens of organization by shutting down the production facilities and letting go of the related resources at some expenses (Helfat \& Peteraf, 2003).

\section{Dynamic Capabilities for Public Sector}

Resource transformation processes that are also known as a resource reconfiguration processes are purposed to manage threats to the organization's competitive advantages. Managing threats or transformation involves reconfiguring and recombining the organizational resources based on the opportunities identified and selected from the environment. The main processes involve redesigning, and realigning the activities and routines of the organizational resources with the environment to create fitness for sustainable growth (Teece, 2007). For the purpose of this article, DCs should be referred to as the ability of a public sector to transform the intangible resources (i.e., staff efficiency) towards organizational performance (i.e., policy development), which is necessary in response to the need of building a strategic plan for the public sector in Malaysia. This is consistent with the concept of DCs that places staff efficiency as an intangible resource, which is important to achieve performance in the public sector. Based on this definition, a concept of DCs for the transformation of public sector is brought into the picture (see Figure 3). This concept of DCs is adapted from Figure 2.

Organizational Resource

Dynamic Capabilities

Organizational Performance

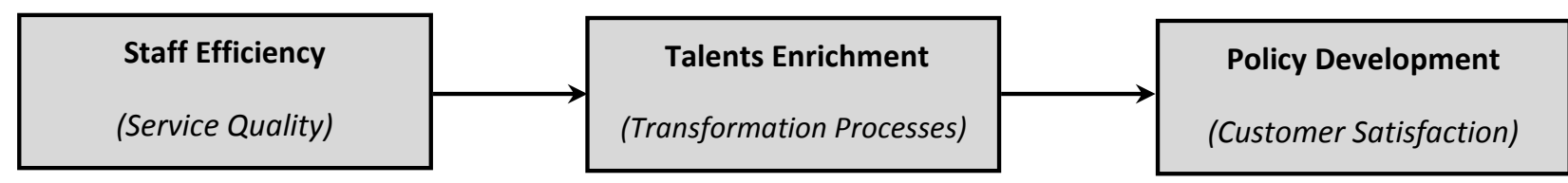

Figure 3: A concept of DCs for the public sector in Malaysia

Although there are five cores of main transformation plan for the public sector in Malaysia (see Table 1), not all of them are relevant in the context of this article as the plan is developed to cater a bigger transformation issues. As such, it was found that only the first core (talents enrichment) is suitable for the transformation processes of staff efficiency. For a record, the second core (organizational reengineering) could be best to transform the organization structure, but this is not the focus of this article. Furthermore, talents enrichment that is to produce public servants with high levels of knowledge, competency, talent, and skill is an important capacity for resource renewal (Helfat \& Peteraf, 2003). To understand how the 
relationship in Figure 3 can be demonstrated with the concept of DCs, it would be important to observe the scores of all items in the element of staff from the study mentioned early.

Table 4: The achievement level and score of the element of staff

\begin{tabular}{lcc}
\hline Item & $\begin{array}{c}\text { Average } \\
\text { Score }\end{array}$ & $\begin{array}{c}\text { Level } \\
\text { (\%) }\end{array}$ \\
\hline $\begin{array}{l}\text { - The influence of skills on staff performance. } \\
\text { - The level of agency efforts to provide training opportunities } \\
\text { among staffs. }\end{array}$ & 2.78 & 69.50 \\
$\begin{array}{l}\text { - Competency enrichment. } \\
\text { - The level of agency efforts to increase spirits and satisfaction } \\
\text { among staffs. }\end{array}$ & 2.68 & 67.75 \\
\hline $\begin{array}{l}\text { - Staffs involvement in the events conducted by the agency. } \\
\text { - The level of effectiveness of Mentor - Mentee program. }\end{array}$ & 2.41 & 63.00 \\
$\begin{array}{l}\text { - The balance between task loads and staffs requirement. } \\
\text { - The implementation level of counselling on staffs. }\end{array}$ & 2.21 & 55.25 \\
\hline
\end{tabular}

As shown in Table 4, all eight items for staff only managed to achieve the average score of less than 3 (out of 4 ) at the level of just under $70 \%$. This implies that the internal respondents, whom are the staffs of the public agency itself, felt that they did not master all the items measuring their capacities to implement the tasks for achieving the objectives. As a result, the transformation processes of staff efficiency towards policy development should be stressed upon all of these items for improvement.

As mentioned before, staff efficiency should be transformed with the first core of transformation plan (talents enrichment). The scores for all items for talents enrichment are summarized in Table 5. As shown in the table, all items have scored full except for one item namely "continuity of leadership among junior officers with senior officials" on the level of importance. Fortunately, this score is still considered as high at 4.5 (out of 5.0). This means the respondents are suggesting that all items for talents enrichment are relevant to be considered for transformation processes of staff efficiency. 
Table 5: The items and scores of the talents enrichment

\begin{tabular}{lccc}
\hline & \multicolumn{3}{c}{ Score } \\
\cline { 2 - 4 } First Core - Talents enrichment & $\begin{array}{c}\text { Importance } \\
(I)\end{array}$ & $\begin{array}{c}\text { Satisfaction } \\
\text { (S) }\end{array}$ & I-S \\
\hline - High ability of the junior officers. & 5.00 & 3.53 & 1.47 \\
$\begin{array}{l}\text { - Strengthening expertise on a continual basis. } \\
\text { - The development of the necessary expertise on an }\end{array}$ & 5.00 & 3.41 & 1.59 \\
$\begin{array}{l}\text { ongoing basis. } \\
\text { - The existence of a group of experts in the relevant fields. }\end{array}$ & 5.00 & 3.40 & 1.60 \\
$\begin{array}{l}\text { - Continuity of leadership among junior officers with } \\
\text { senior officials. }\end{array}$ & 4.50 & 3.46 & 1.04 \\
\hline
\end{tabular}

Therefore, it can be understood that the transformation processes with talents enrichment can be deployed to improve the current resources performance (i.e., staff efficiency) in response to the environmental change. This can be done by building and stressing upon the ability of the apprentices, continuous inaugural of expertise, continuous development of the necessary expertise, the existence of a group of expertise in related fields, and the continuity of leadership between junior and senior officers.

\section{Proposition for Future Study}

This article has so far shown the importance of relationship between staff efficiency and policy development from a recent study in one agency of the public sector in Malaysia. On top of that, this article has suggested the relevance of talents enrichment to transform staff efficiency towards a better policy development. As such, this article has focused on the first core of transformation plan for the public sector in Malaysia, i.e., talents enrichment as the capacity for the transformation processes in the concept of DCs. As a result, a framework of DCs for the public sector has been conceptualized in Figure 3. Although this article has identified staff efficiency and policy development as critical to the public sector, there was no further empirical analysis looking at the relationships between them when mediated by talents enrichment. For this reason, the relationships should be empirically tested to support the concept of DCs for the public sector. As shown in Figure 4, a set of propositions are suggested for future empirical study, namely:

P1: Staff efficiency is related to the policy development of public sector

P2: Staff efficiency is related to the resource transformation processes of talents enrichment

P3: Talents enrichment is related to the policy development of public sector

P4: Talents enrichment is mediating the effect of staff efficiency on the policy development of public sector 


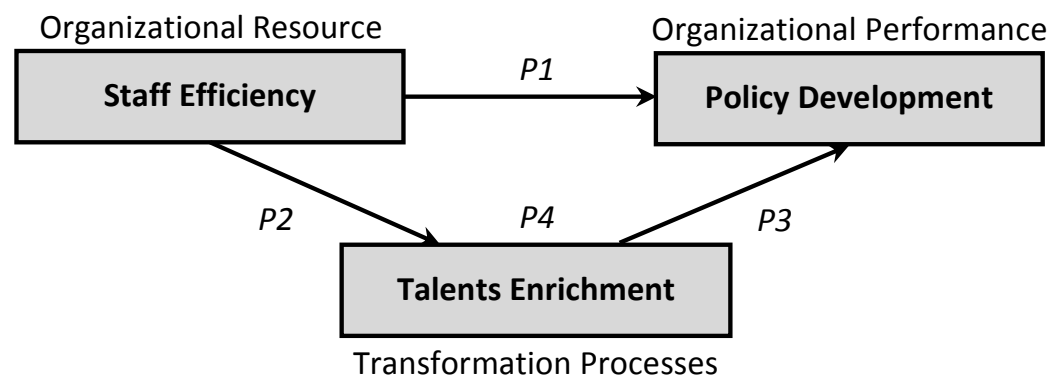

Figure 4: A proposition for future empirical study

\section{Contributions}

This article has supported the previous works on the application of DCs as a strategic tool to improve the organization performance in the public sector (Pablo, Reay, Dewald, \& Casebeer, 2007). This implies that the concept of DCs is not impossible to be implemented and is highly relevant to be applied in the public sector to increase the success rate of long-term strategic planning. The discussion is also consistent with the use of DCs as a strategic approach to understand changes in strategy (Helfat \& Peteraf, 2009). Since the discussion is based on the actual data and facts (in addition to the literature review) that were taken from a recent study in one agency of the public sector in Malaysia, this article has shown that talents enrichment (first core of transformation plan) is the action form for resource transformation processes in DCs for the public sector. Meanwhile, the discussion that stressed upon the staffs transformation processes to achieve better policy development is implying that the concept of DCs is not just to achieve the financial objective, but also the non-financial objective (Helfat, et. al., 2007). Consequently, it is a necessity for the future study to assure that the discussion will not stop at the conceptual level. As a result, the proposed conceptual framework should be advanced for empirical investigation to statistically test the mediating effect of talents enrichment (transformation processes) in the relationship between staff efficiency and policy development.

\section{Limitations}

This article is neither to report on the details of the study highlighted here, nor the development processes of the strategic plan in the said agency of the public sector in Malaysia. Instead, this article is more towards using of the relevant information from the study to justify on a concept of DCs for the public sector focusing on the transformation processes. Meanwhile, since the data were taken directly from the study that was not specifically designed for this article, the interpretation of the findings highlighted in this article does not necessarily mirror the conclusions made by the study. This happens due to the article was only considering two variables investigated in the study, namely the element of staff, and the dimension of policy development, besides talents enrichment (transformation processes). However, this does not necessarily means that the article has rejected the importance of other variables, but purposely avoiding making any discussion on them as to concentrate on the concept of DCs. Furthermore, although possible actions have been considered to carefully translate the original text on the 
transformation plan from Malay to English, there could still be some imperfection in the processes. As such, the original version of the transformation plan should be referred to when necessary. Lastly, this article was purposely giving loose information on the highlighted study from the said agency to maintain anonymity.

\section{Conclusions}

In summary, the element of staff, the dimension of policy development, and the main cores of transformation plan discussed in this article to advance the concept of DCs are based on the actual study in the public sector of Malaysia. The concept has clearly placed staff efficiency as a valuable intangible resource, policy development as the performance to be achieved, while the first core of transformation plan (talents enrichment) as the element for resource transformation processes. This shows that the activities to develop the strategic plan in the public sector of Malaysia can be understood with the concept of DCs. Although this concept is still not very widely applied in the public sector, the concept has proven that DCs is actually being used by the public sector in Malaysia to implement the transformation plan via talents enrichment. As a result, it is clear that this concept can be used not only by the profit-centered organizations, but also by the non-business related organizations. This will definitely contribute to the knowledge and continuous development of the concept of DCs. Besides that, the related relationships in the concept could be further investigated for empirical evidences. As a conclusion, this article has managed to clarify some of the issues regarding the concept of DCs, in a form of transformation processes for the public sector in Malaysia.

\section{References}

Czakon, W. (2009). Relational capability of organizations - theoretical advances. Journal of economics and management, 5, 47-65.

DiStefano, G., Peteraf, M., \& Verona, G. (2010). Dynamic capabilities deconstructed: a bibliographic investigation into the origins, development, and future directions of the research domain. Industrial and Corporate Change, 19(4), 1187-1204. doi:10.1093/icc/dtq027

Ellonen, H.-K., Wikstrom, P., \& Jantunen, A. (2009). Linking dynamic capability portfolios and innovation outcomes. Technovation, 29, 753-762. doi:10.1016/i.technovation.2009.04.005

Eriksson, T. (2014). Processes, antecedents and outcomes of dynamic capabilities. Scandinavian Journal of Management, 30(1), 65-82. doi:10.1016/i.scaman.2013.05.001

Hanafizadeh, P., \& Ravasan, A. Z. (2011). A McKinsey 7S model-based framework for ERP readiness assessment. International journal of enterprise information systems, 7, 23-63. doi:10.4018/jeis.2011100103

Helfat, C. E., \& Peteraf, M. A. (2003). The dynamic resource-based view: capability lifecycles. Strategic management journal, 24, 997-1010. doi:10.1002/smj.332

Helfat, C. E., Finkelstein, S., Mitchell, W., Peteraf, M. A., Singh, H., Teece, D. J., \& Winter, S. G. (2007). Dynamic capabilities: understanding strategic change in organizations. USA: Blackwell Publishing.

Helfat, C., \& Peteraf, M. (2009). Understanding dynamic capabilities: progress along a developmental path. Strategic organization, 7(1), 91. doi:10.1177/1476127008100133 
Pablo, A. L., Reay, T., Dewald, J. R., \& Casebeer, A. L. (2007). Identifying, enabling and managing dynamic capabilities in the public sector. Journal of management studies, 44(5), 687-708. doi:10.1111/j.1467-6486.2006.00675.x

Salomo, S., Gemunden, H. G., \& Leifer, R. (2007). Research on corporate radical innovation systems - a dynamic capabilities perspective: an introduction. Journal of engineering and technology management, 24, 1-10. doi:10.1016/j.jengtecman.2007.01.001

Teece, D. J. (2007). Explicating dynamic capabilities: the nature and microfoundations of (sustainable) enterprise performance. Strategic management journal, 28(13), 1319-1350. doi:10.1002/smj.640

Teece, D. J., Pisano, G., \& Shuen, A. (1997). Dynamic capabilities and strategic management. Strategic management journal, 18(7), 509-533. doi:10.1002/(SICl)10970266(199708)18:7<509::AID-SMJ882>3.0.CO;2-Z

Wang, C. L., \& Ahmed, P. K. (2007). Dynamic capabilities: a review and research agenda. International journal of management reviews, 9(1), 31-51. doi:10.1111/j.14682370.2007.00201.x

$\mathrm{Wu}$, L.-Y. (2009). Applicability of the resource-based and dynamic-capability views under environmental volatility. Journal of business research, 1-5. doi:10.1016/j.jbusres.2009.01.007 Zahra, S. A., Sapienza, H. J., \& Davidsson, P. (2006). Entrepreneurship and dynamic capabilities: a review, model and research agenda. Journal of management studies, 43(4), 917-955. doi:10.1111/j.1467-6486.2006.00616.x 